\title{
Assessing Students' Attainment in Learning Outcomes: A Comparison of Course-End Evaluation and Entry-Exit Surveys
}

\author{
Andy Ka-Leung $\mathrm{Ng}^{1, *}$, Kai-Ming Kiang ${ }^{1} \&$ Derek Hang-Cheong Cheung ${ }^{1}$ \\ ${ }^{1}$ Office of University General Education, Baldwin Cheng Research Centre for General Education, The Chinese \\ University of Hong Kong, Shatin, Hong Kong \\ *Correspondence: Office of University General Education, The Chinese University of Hong Kong, Shatin, Hong Kong. \\ Tel: 852-3943-9710. E-mail: andyklng@cuhk.edu.hk
}

Received: April 24, 2016

Accepted: May 29, 2016 Online Published: June 3, 2016

doi:10.5430/wje.v6n3p56

URL: http://dx.doi.org/10.5430/wje.v6n3p56

\begin{abstract}
The traditional course-end evaluation for the general education courses at The Chinese University of Hong Kong can gauge student's perception of their attainment of the intended learning outcomes at the end of the course but can hardly reflect the changes of their perception from the beginning to the end. In order to trace the change in students' perception regarding the intended learning outcomes of the General Education Foundation course In Dialogue with Nature, a new assessment method that contains a pair of surveys with a set of identical questions, namely entry survey and exit survey, were developed and conducted at the beginning and at the end of the course correspondingly. While both assessment methods showed that the course was well-received, inconsistencies were identified and that the entry-exit surveys reveal additional aspects which could be overlooked with the traditional course-end evaluation. The study may suggest that entry-exit surveys provide a more truthful representation of students' perceived attainment of the intended learning outcomes and sheds light on the development of course assessment strategies in general.
\end{abstract}

Keywords: general education; course evaluation; survey; learning outcomes; assessment

\section{Introduction}

The education reform in Hong Kong in 2012 sets a milestone for the development of general education in The Chinese University of Hong Kong (CUHK). Extra resources has been put into general education, in the hope of providing a more balanced undergraduate education for all students (Office of University General Education, 2013a). One of the changes is the full launch of the General Education Foundation (GEF) Programme which is made compulsory for all undergraduate students starting from 2012, in addition to the existing distribution requirement in general education. GEF consists of two courses, namely, In Dialogue with Humanity and In Dialogue with Nature. In both of these courses, students read the selected classic texts and engage in discussion with teachers and peers towards the enduring questions of humankind. The course In Dialogue with Humanity invites students to reflect on the meaning of good life with emphasis on love, friendship and religions; and on the principles of an ideal society and the balance between self-interest and common good (Office of University General Education, 2013b). For the course In Dialogue with Nature, students would trace the historical development of physical and life sciences and reflect on the contribution and limitation of the scientific methods. They would also compare the views of nature in the West and the Far East (Office of University General Education, 2013c). Through the two courses, students are expected to get acquainted with the following qualities (Programme ILOs) (Office of University General Education, 2013d):

1. a knowledge of major ideas that shape the world today;

2. an intellectual inquisitiveness in addressing issues related to their life and society;

3. the willingness and capacity to examine new and different ideas;

4. the ability to engage in intensive and close reading; and

5. the readiness to articulate their own ideas clearly and systematically in writing and oral communication. 
Apart from the Programme ILOs, each of the two courses also has its own ILOs (Course ILOs) that students are expected to attain. In this paper, the emphasis is on the course In Dialogue with Nature, with the Course ILOs as follows (Office of University General Education, 2013c):

1. read and discuss science texts with confidence;

2. identify the essential characteristics of various methods of scientific inquiry that have significant impacts on how human beings view life and universe;

3. formulate informed personal views on the societal implications of scientific explorations;

4. relate the development in natural sciences highlighted in the course to contemporary human conditions; and

5. evaluate the scopes of application, achievement and limitations of highlighted scientific methods using multiple perspectives.

Students are expected to attain these Programme ILOs and Course ILOs through intensive reading of science-related classical texts, in-depth discussion of various enduring questions and articulation of their own reflections in written assignments. The selected texts of In Dialogue with Nature is shown in Table 1.

Table 1. Reading List for In Dialogue with Nature

\section{Part I: Human Exploration of the Physical Universe}

- Republic / Plato

- The Beginnings of Western Science / David C. Lindberg

- The Birth of a New Physics / I. Bernard Cohen

- The Principia: Mathematical Principles of Natural Philosophy / Isaac Newton

Part II: Human Exploration of the World of Life

- On The Origin of Species / Charles Darwin

- DNA: The Secret of Life / James D. Watson

- Silent Spring/Rachel Carson

\section{Part III: Our Understanding of Human Understanding}

- Science and Method / Henri Poincaré

- In Search of Memory: The Emergence of a New Science of Mind / Eric R. Kandel

- The Shorter Science and Civilisation in China / Joseph Needham

- Why the Scientific Revolution Did Not Take Place in China - or Didn't It? / Nathan Sivin

- Brush Talks from Dream Brook / Shen Kua

- The Mathematical Universe / William Dunham

- Elements / Euclid

Since the full launch of GEF, students have generally provided a positive feedback from the course-end evaluation survey and in the focus group interviews. It is noted however, that the survey is conducted at the end of the course and the measurement on the attainment of ILOs is performed in a retrospective way. Students are required to self-evaluate whether they have improvement in attaining the ILOs at the end of the course. This kind of measurement may not accurately reflect the change of student's perception on the ILOs as it is hard for the students to recall their status 3 or 4 months ago and to make comparison to their current status on the spot. The presented study in this paper involves the use of two student surveys, namely entry and exit surveys, which contains a set of identical questions to measure students' perception of their ILO attainment at the beginning and at the end of their study in the course In Dialogue with Nature. The data gathered in the entry survey can act as a defined baseline to trace the change of the student's status. One is then possible to more accurately judge the effectiveness of the course by looking at the degree of improvement (Astin, 2012).

This paper aims at reporting, first, the design of the entry-exit surveys, and second, the comparison of the results 
between course-end evaluation and the entry-exit surveys. Both surveys were conducted for the 2014-15 fall term obtained from twelve classes of In Dialogue with Nature.

\section{Results of Course-end Evaluation}

Course and Teaching Evaluation (CTE) is a regular practice in higher education to collect students' opinion of the course and the course teacher (Kember \& Leung, 2011). It has been well-documented that student ratings are reliable in measuring teaching effectiveness (Feldman, 2007; Marsh \& Dunkin, 1997).

At the GEF Programme of CUHK, CTE is usually administered at the end of a course in the form of a hardcopy questionnaire. The first part of the CTE requires students to evaluate classroom teaching and the course content, which is a university-wide practice looking at teaching effectiveness. The second part of the CTE asks students to reflect on their efforts and achievements throughout the course. The second part, which is the focus of this paper, contains eleven statements as shown in Table 2. These questions are dedicated to understand students' perception of their improvement towards the ILOs after taking the course. Students were asked to rate in a 6-point Likert scale (from strongly disagree to strongly agree) whether they have 'more' or are 'better' in regards to the aspects referred by these eleven statements. The results of this course-end evaluation from the twelve classes $(n=272)$ of In Dialogue with Nature in 2014-15 fall term are shown in Table 2. Students generally perceived that they have improved in all aspects, with an average score of 4.58 (ranges from 4.13 to 4.93 ). This suggests that students found the course effective in helping them to achieve the ILOs.

The eleven ILO-related statements can be classified according to Bloom's taxonomy (Bloom, Engelhart, Furst, Hill, \& Krathwohl, 1956; Krathwohl, Bloom, \& Masia, 1964). Questions 22 and 25 belong to the affective domain. The remaining questions (Q23-24, Q26-32) belong to the cognitive domain. Questions in the cognitive domain can be subdivided into Programme ILOs-related questions (Q23, 24, 26-29) that concerns the generic skills and Course ILOs-related questions (Q30-32) that concerns the disciplinary knowledge. Judging from the averages of the three categories, students reported to have the greatest improvement in the ILOs in the affective domain (Average: 4.70), followed by the course ILOs (Average: 4.62) and programme ILOs (Average: 4.53) in the cognitive domain.

Table 2. Results of Course-end Evaluation (in a 6-Point Likert scale) $(\mathrm{n}=272)$

\begin{tabular}{llll}
\hline Category & Statements & CTE & Average \\
\hline Affective & Q22. I am more interested in the subject matter of this course. & 4.49 & 4.70 \\
domain & Q25. I can better appreciate the value of disciplines beyond my major. & 4.92 & \\
\hline Cognitive & Q23. I can analyze and evaluate arguments more critically. & 4.81 & 4.53 \\
domain: & Q24. I can apply the knowledge gained in this course to related issues. & 4.66 & \\
Programme & Q26. I am more open to new and different ideas. & 4.93 & \\
ILOs & Q27. I am more confident in reading difficult texts. & 4.13 & \\
& Q28. I can better articulate my ideas in writing. & 4.31 & \\
& Q29. I can better express my ideas orally. & 4.32 & \\
\hline Cognitive & Q30. I can identify various features of scientific methods. & 4.59 & 4.62 \\
domain: & Q31. I can better appreciate the contributions and limitations of & 4.70 & \\
Course & QLOs & & \\
& scientific inquiry. & & \\
& Q32. I can formulate informed views on the social implications of & 4.56 & \\
\hline & scientific inquiry. & & \\
\hline
\end{tabular}

\section{Design and Results of Entry-Exit Surveys}

Entry-exit surveys were developed and conducted in 2014-15 fall term for the course In Dialogue with Nature. The surveys measure students' perception towards the ILOs at the beginning and at the end of the course. These two time points serve as the two most representative milestones of the course for gauging the change of students' status.

The design of the entry and exit surveys is shown in Appendices 1 and 2 respectively. Students were assigned a three-digit number at the entry survey. They were asked to record the number and recall it at the time of exit survey. Since the number was only known to that particular student, it allows tracking of the change of perception towards the ILOs of individual students and at the same time preserving anonymity.

Both surveys contain a set of twelve identical ILO-related statements which students rated in a 6-point Likert scale (from strongly disagree to strongly agree). These twelve statements were designed based on the eleven statements in 
the course-end evaluation, with some changes as follows. First, instead of asking students for their perceived improvement of the ILOs as in the course-end evaluation, the entry-exit surveys ask the students to report their current status of ILO attainments. Second, since some of the statements were shared by the two GEF courses in the course-end evaluation, some alterations, addition and deletion were made to turn them into statements more specific to the course In Dialogue with Nature. Apart from the responses towards the twelve statements, the surveys also collect students' backgrounds, their effort spent on the course, and their views toward the effectiveness of various learning methods. This survey tool was also used to assess the effectiveness of a series of supplementary lectures and the results were published (Kiang, $\mathrm{Ng}$, \& Cheung, 2015).

A total of 282 and 270 students in the surveyed classes took part in the entry and exit surveys respectively. Change of student enrolment status and class attendance lead to the difference in numbers in the two surveys. Two students left the class early after the course-end evaluation and did not complete the exit survey.

Their average scores towards the twelve ILO-related statements are tabulated in Table 3. The exit scores are all higher than the entry scores. The increments $(\triangle)$ are indicated by the positive values when the entry scores are subtracted from the exit scores in the second last column. These increments range from +0.24 to +1.39 , with an average of +0.67 , suggesting that the course In Dialogue with Nature has met its intended goals.

Table 3. Results of Entry-Exit Surveys (in a 6-Point Likert Scale) (Entry: $n=282$; Exit: $n=270$ )

\begin{tabular}{llllll}
\hline Category & Statements & $\begin{array}{l}\text { Entr } \\
\mathbf{y}\end{array}$ & $\begin{array}{l}\text { Exi } \\
\mathbf{t}\end{array}$ & $\triangle^{*}$ & $\Delta$ Average \\
& & 4.11 & 4.71 & +0.59 & +0.52 \\
\hline Affective & Q1. I am interested in natural science. & 4.83 & +0.44 & \\
domain & Q3. Scientific knowledge is important for my intellectual \\
& pursuit. & 4.39 & & & \\
\hline Cognitive & Q4. I can analyze and evaluate arguments critically. & 4.08 & 4.71 & +0.62 & +0.44 \\
domain: & Q5. I am open to new and different ideas. & 4.79 & 5.03 & +0.24 & \\
Programme & Q6. I am confident in reading science-related texts. & 3.94 & 4.39 & +0.45 & \\
ILOs & Q7. I am confident in reading difficult texts in English. & 3.62 & 4.05 & +0.43 & \\
& Q8. I can articulate clearly my ideas in writing. & 3.96 & 4.42 & +0.46 & \\
& Q9. I can express clearly my ideas orally. & 3.93 & 4.37 & +0.44 & \\
\hline Cognitive & Q2. I understand the development of natural science. & 3.04 & 4.43 & +1.39 & +1.09 \\
domain: & Q10. I understand various features of scientific methods. & 3.68 & 4.61 & +0.93 & \\
Course & Q11. I understand the contributions and limitations of & 3.78 & 4.77 & +0.99 & \\
ILOs & scientific inquiry. & & & & \\
& Q12. I can assess the social implications of scientific inquiry. & 3.70 & 4.73 & +1.03 & \\
\hline
\end{tabular}

Notes: $* \triangle$ indicates Exit scores minus Entry scores.

Similar to the course-end evaluation, the twelve statements are classified according to Bloom's taxonomy (Bloom et al., 1956; Krathwohl et al., 1964). Questions 1 and 3 are grouped into the affective domain. The average increment of students' perception in this domain is +0.52 . The remaining questions are grouped under the cognitive domain. Questions 4 to 9 are derived from the Programme ILOs, which concerns the generic skills, and has an average increment of students' perception of +0.44 . Questions 2, 10 to 12 are derived from the Course ILOs, which are related to disciplinary knowledge. The average increment in this category is +1.09 , which is more than twice of any of the two other categories.

\section{Comparison of Course-end Evaluation and Entry-Exit Surveys}

Since both the course-end evaluation and the entry-exit surveys are tools that are supposed to measure students' perceived change in their attainments in the ILOs, intuitively, the result should reflect a similar pattern. Interestingly, when the three categories in the entry-exit surveys and the course-end evaluation are compared, both the rankings and degree of improvement differ. Students reported in the entry-exit surveys that they had the greatest improvement in the course ILOs (an average increment of 0.57 and 0.65 higher than the two other categories). In contrast, they reported in the course-end evaluation that their improvement in the course ILOs ranked the second and the differences among the three categories are only marginal (0.08-0.17 in a 6-point scale). These discrepancies in the results of the two assessment tools suggest that there could be some underlying systematic problem in using these 
tools and it is therefore important to find out which tool can provide a more accurate measurement of students' perceived improvement of ILO attainment.

A more refined analysis on the statements in the course-end evaluation and the entry-exit surveys has been conducted. Nine pairs of statements in the two assessment tools are identified to be addressing the same ILO. These pairs are denoted by letters (a) to (i) in Table 4. The analysis as follows is confined to these nine pairs. The remaining two statements in the course-end evaluation and three statements in the entry-exit surveys were not paired as they are addressing different ILOs. These nine statements are arranged in a descending order of the scores (course-end evaluation) or scores increment (entry-exit surveys) (Table 4). If the two tools provide a similar representation in the degree of perceived improvement in ILOs, the letters in the two lists would be ordered similarly. However, such similarity is not clearly indicated.

Table 4. Comparison of the Nine Statement Pairs in the Course-End Evaluation and Entry-Exit Surveys

\begin{tabular}{|c|c|c|c|c|c|}
\hline Course-end Evaluation & Scores & & & Entry-Exit Surveys & $\triangle *$ \\
\hline $\begin{array}{l}\text { Q26. I am more open to new and } \\
\text { different ideas. [Programme ILO] }\end{array}$ & 4.93 & (a) & (e) & $\begin{array}{l}\text { Q12. I can assess the social } \\
\text { implications of scientific inquiry. } \\
\text { [Course ILO] }\end{array}$ & +1.03 \\
\hline $\begin{array}{l}\text { Q23. I can analyze } \text { and evaluate } \\
\text { arguments critically. } \\
\text { [Programme ILO] }\end{array}$ & 4.81 & (b) & (c) & $\begin{array}{l}\text { Q11. I understand the contributions } \\
\text { and limitations of scientific inquiry. } \\
\text { [Course ILO] }\end{array}$ & +0.99 \\
\hline $\begin{array}{l}\text { Q31. I can better appreciate the } \\
\text { contributions and limitations of } \\
\text { scientific inquiry. [Course ILO] }\end{array}$ & 4.70 & (c) & (d) & $\begin{array}{l}\text { Q10. I understand various features } \\
\text { of scientific methods. [Course ILO] }\end{array}$ & +0.93 \\
\hline $\begin{array}{l}\text { Q30. I can identify various features of } \\
\text { scientific methods. [Course ILO] }\end{array}$ & 4.59 & (d) & (b) & $\begin{array}{l}\text { Q4. I can analyze and evaluate } \\
\text { arguments critically. [Programme } \\
\text { ILO] }\end{array}$ & +0.62 \\
\hline $\begin{array}{l}\text { Q32. I can formulate informed views } \\
\text { on the social implications of scientific } \\
\text { inquiry. [Course ILO] }\end{array}$ & 4.56 & (e) & (f) & $\begin{array}{l}\text { Q1. I am interested in natural } \\
\text { science. [Affective] }\end{array}$ & +0.59 \\
\hline $\begin{array}{l}\text { Q22. I am more interested in the } \\
\text { subject matter of this course. } \\
\text { [Affective] }\end{array}$ & 4.49 & (f) & (h) & $\begin{array}{l}\text { Q8. I can articulate clearly my ideas } \\
\text { in writing. [Programme ILO] }\end{array}$ & +0.46 \\
\hline $\begin{array}{l}\text { Q29. I can better express my ideas } \\
\text { orally. [Programme ILO] }\end{array}$ & 4.32 & (g) & (g) & $\begin{array}{l}\text { Q9. I can express clearly my ideas } \\
\text { orally. [Programme ILO] }\end{array}$ & +0.44 \\
\hline $\begin{array}{l}\text { Q28. I can better articulate my ideas in } \\
\text { writing. [Programme ILO] }\end{array}$ & 4.31 & (h) & (i) & $\begin{array}{l}\text { Q7. I am confident in reading } \\
\text { difficult texts in English. } \\
\text { [Programme ILO] }\end{array}$ & +0.43 \\
\hline $\begin{array}{l}\text { Q27. I am more confident in reading } \\
\text { difficult texts. [Programme ILO] }\end{array}$ & 4.13 & (i) & (a) & $\begin{array}{l}\text { Q5. I am open to new and different } \\
\text { ideas. [Programme ILO] }\end{array}$ & +0.24 \\
\hline
\end{tabular}

Notes: (1)* $\triangle$ indicates Exit scores minus Entry scores; (2) Content in the brackets [ ] denotes the categories of the ILO-related statements.

Two pieces of information could give some hints to determine which of the two assessment tools provides a more truthful representation.

First, Jamie and others have indicated that students generally focus more on the disciplinary knowledge in a course, rather than the generic skills that they acquire along the way (Jamie, George, Dickson, Engelsman, \& Kay, 2003). This claim coheres with the trend of students' perceived enhancement in the entry-exit surveys, which shows that the statements related to course ILOs have greater increment than the statements related to programme ILOs (Table 4). Such trend was however not observed in the course-end evaluation.

Second, and surprisingly, a comparison of the exit survey and the course-end evaluation reveals that their scores toward the paired statements are highly similar (Table 5). The former is an end-point measurement tool while the latter presumably measures the degree of improvement of ILOs. The two sets of scores in the pair were subject to two-tail unpaired Student's t-test. Out of the nine statement pairs, seven (Pairs 1-7) have highly similar scores (with no statistically significant differences) between the course-end evaluation and the exit survey. It is suspected that 
students may not distinguish the statements and treat both as end-point measurements. For example, students may perceive the statement "I am more open to new and different ideas" in the course-end evaluation as "I am open to new and different ideas" (Pair 1). The remaining two statement pairs (Pairs 8-9) have significantly different scores between the two tools. This may be because the wordings in these pairs are not as similar as those in Pairs 1-7.

Taking these evidences into consideration, it is likely that the entry-exit surveys provide more truthful representations of students' perception of ILO attainment.

Table 5. Scores Comparison of Statement Pairs in Course-End Evaluation and Exit Survey

\begin{tabular}{llllc}
\hline Pairs & Tools & Statements & Scores & $\boldsymbol{p}^{*}$ \\
\hline 1 & CTE & I am more open to new and different ideas. & 4.93 & 0.15 \\
& Exit & I am open to new and different ideas. & 5.03 & \\
2 & CTE & I can analyze and evaluate arguments more critically. & 4.81 & 0.13 \\
& Exit & I can analyze and evaluate arguments critically. & 4.71 & \\
3 & CTE & I am more confident in reading difficult texts. & 4.13 & 0.40 \\
& Exit & I am confident in reading difficult texts in English. & 4.05 & \\
4 & CTE & I can better articulate my ideas in writing. & 4.31 & 0.12 \\
& Exit & I can articulate clearly my ideas in writing. & 4.42 & \\
5 & CTE & I can better express my ideas orally. & 4.32 & 0.54 \\
& Exit & I can express clearly my ideas orally. & 4.37 & \\
6 & CTE & I can better appreciate the contributions and limitations of scientific inquiry. & 4.70 & 0.32 \\
& Exit & I understand the contributions and limitations of scientific inquiry. & 4.77 & \\
7 & CTE & I can identify various features of scientific methods. & 4.59 & 0.82 \\
\multirow{2}{*}{8} & Exit & I understand various features of scientific methods. & 4.61 & \\
& CTE & I am more interested in the subject matter of this course. & 4.49 & 0.01 \\
9 & Exit & I am interested in natural science. & 4.71 & \\
& CTE & I can formulate informed views on the social implications of scientific inquiry. & 4.56 & 0.02 \\
& Exit & I can assess the social implications of scientific inquiry. & 4.73 & \\
\hline
\end{tabular}

Note: * The scores in each pair are subject to two-tail unpaired Student' $\mathrm{st}$ t-test, $\mathrm{p} \leqslant .05$ is regarded as statistical significant.

\section{Conclusion}

A new course assessment method, the entry-exit surveys, for the GEF course In Dialogue with Nature was reported. This survey tool enables the study of the enhancement of ILOs from a new perspective besides the traditional course-end evaluation.

Both entry-exit surveys and course-end evaluation showed positive student feedbacks. It is, however, unexpected to notice the discrepancies in the results of entry-exit surveys and course-end evaluation. This prompted the study of identifying the tool that provides more accurate measurement to students' perception of ILOs improvement. Previous research and comparison of questionnaire items show that entry-exit surveys could provide more truthful representation.

The study raised the question of the validity of using course-end evaluation as a sole measurement in gauging students' perceived improvement of ILOs. Teachers and school admininstrators should aware that course-end evaluation may be suitable for measuring students' perceived attainment, rather than improvement, of ILOs. When ILOs improvement is of particular concern, entry-exit surveys could be more appropriate for addressing the needs. It is noted that, more could be done in the future to look into the scope of application and limitations of entry-exit surveys, for instance, the applicability of the tool in all three domains in Bloom's taxonomy of learning outcomes and the possibility of students' self-complacency in the exit survey.

\section{Acknowledgements}

This research is partially funded by the Micro-Module Courseware Development Grant at The Chinese University of Hong Kong with project titles "Effects and Risks on Micro-module Implementation in UGFN1000" and "Micro-modules for UGFN1000 classroom flipping".

For conducting the entry-exit surveys and data analysis, we are in-debt to our colleagues in the Office of the 
University General Education in The Chinese University of Hong Kong including Prof. LEUNG Mei-Yee, Dr. WONG Wing-Hung, Ms. WONG Carina, and Miss LAI Ann.

\section{References}

Astin, A. (2012). Assessment for Excellence: The Philosophy and Practice of Assessment and Evaluation in Higher Education (2nd ed.). Lanham: Rowman \& Littlefield Publishers.

Bloom, B. S., Engelhart, M. D., Furst, E. J., Hill, W. H., \& Krathwohl, D. R. (1956). Taxonomy of educational objectives: The classification of educational goals. Handbook I: Cognitive domain. New York, NY: Longmans, Green and Co.

Feldman, K. A. (2007). Identifying exemplary teachers and teaching: Evidence from student ratings. In R. P. Perry \& J. C. smart (Eds.), The scholarship of teaching and learning in higher education: An evidence-based perspective (pp. 93-126). New York, NY: Springer.

Jamie, I. M., George, A. V., Dickson, N. J., Engelsman, M., \& Kay, D. (2003). Learning generic skills in first year chemistry. Proceedings of Improving Learning Outcomes Through Flexible Science Teaching.

Kiang, K. M., Ng, A. K. L., \& Cheung, D. H. C. (2015). Teaching Science to Non-Science Students with Science Classics. American Journal of Educational Research, 3(10), 1291-1297.

Kember, D., \& Leung, D. Y. P. (2011). Disciplinary differences in student ratings of teaching quality. Research in Higher Education, 52(3), 278-299. http://dx.doi.org/10.1007/s11162-010-9194-z

Krathwohl, D. R., Bloom, B. S., \& Masia, B. B. (1964). Taxonomy of educational objectives: The classification of educational goals. Handbook II: The affective domain. New York, NY: David McKay.

Marsh, H. W., \& Dunkin, M. J. (1997). Students' evaluations of university teaching: A multidimensional perspective. In R. P. Perry \& J. C. smart (Eds.), Effective teaching in higher education: Research and practice (pp. 241-320). New York, NY: Agathon Press.

Office of University General Education. (2013a). Our Missions. Retrieved from https://www5.cuhk.edu.hk/oge/index.php/en/overview/mission

Office of University General Education. (2013b). Why Humanity? Retrieved from http://www5.cuhk.edu.hk/oge/index.php/en/2011-06-22-08-12-11/why-humanity

Office of University General Education. (2013c). Why Nature? Retrieved from http://www5.cuhk.edu.hk/oge/index.php/en/2011-06-22-08-12-11/why-nature

Office of University General Education. (2013d). Mission \& Vision. Retrieved from http://www5.cuhk.edu.hk/oge/index.php/en/gef-overview/mission-a-vision 


\section{Appendices}

Appendix 1. Entry Survey.

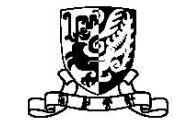

The Chinese University of Hong Kong

Office of University General Education Investigation on Effective Learning Methods
The aim of this survey is to understand students' learning methods in relation to the learning outcomes of the course UGFN. Your response will be kept strictly confidential, and will be used for research purposes only. Only aggregated and anonymized results will be reported in publications

Your participation is entirely voluntary. If you have any questions or concerns, please contact your teacher. Thank you for your cooperation.

Use black / blue ball pens only. Right
Wrong $\ominus \otimes \otimes$

Survey Tag
\begin{tabular}{|l|l|l|}
\hline & & \\
\hline & & \\
\hline$(0)$ & (0) & $(0)$ \\
(1) & (1) & $(1)$ \\
(2) & (2) & $(2)$ \\
(3) & (3) & $(3$ \\
(4) & (4) & $(4)$ \\
(5) & (5) & $(5)$ \\
(6) & (6) & $(6$ \\
(7) & (7) & 7 \\
(8) & (8) & (8) \\
(9) & (9) & (9)
\end{tabular}

1. I am interested in natural science. 我對自然科學有興趣

2. I understand the development of natural science. 我了解自然科學的發展歷程

3. Scientific knowledge is important for my intellectual development. 科學知識對我的個人智性發展是重要的

4. I can analyze and evaluate arguments critically. 我能以批判的眼光去分析及評價不同的論點

5. I am open to new and different ideas. 我可以接受新的、不同的想法

6. I am confident in reading science-related texts. 我有信心閲讀與科學有關的文章

7. I am confident in reading difficult texts in English. 我有信心以英語閲讀鞎深的文章

8. I can articulate clearly my ideas in writing. 我能清晰地以文字說明自己的想法

9. I can express clearly my ideas orally. 我能清晰地以口頭表详說明自己的想法

10. I understand various features of scientific methods. 我了解科學方法的特徵

11. I understand the contributions and limitations of scientific inquiry. 我了解科學探究的貢獻及局限

12. I can assess the social implications of scientific inquiry. 我能評價科學探究對社會的影響

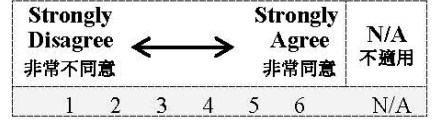

1. 0000000

2. $\bigcirc 000000$

3. $\bigcirc 000000$

4. 0000000

5. 0000000

6. 0000000

7. 0000000

8. $\bigcirc \circ \bigcirc \bigcirc \bigcirc 00$

9. 00000000

10. 0000000

11.0000000

12. $\bigcirc \circ \bigcirc \bigcirc \bigcirc 00$

Your Background:

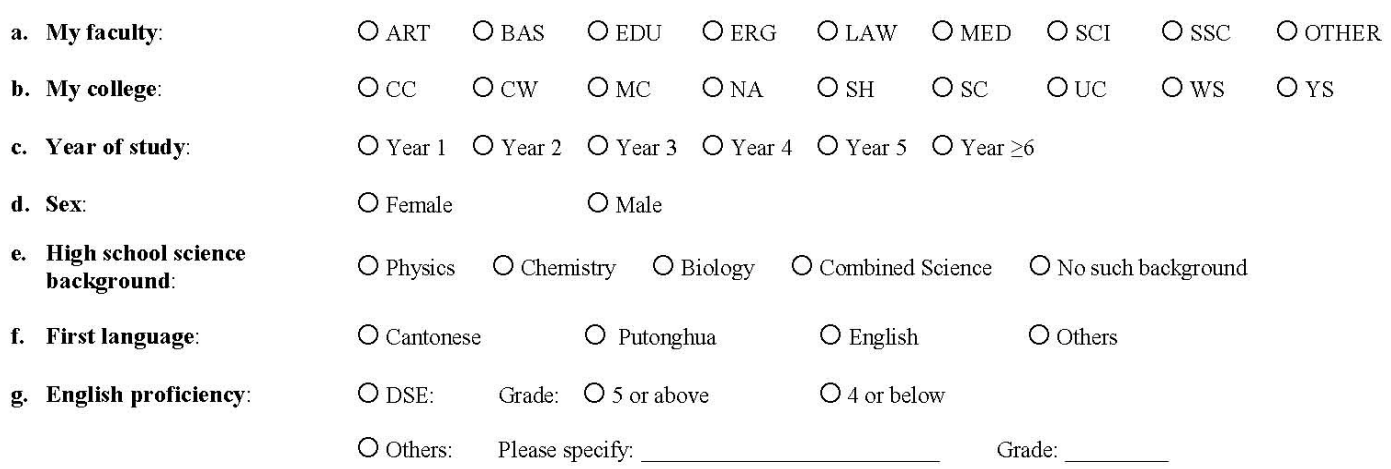


Appendix 2. Exit Survey.

The Chinese University of Hong Kong

Office of University General Education

Investigation on Effective Learning Methods

The aim of this survey is to understand students' learning methods in relation to the learning outcomes of the course UGFN. Your response will be kept strictly confidential, and will be used for research purposes only. Only aggregated and anonymized results will be reported in publications

Your participation is entirely voluntary. If you have any questions or concerns, please contact your teacher. Thank you for your cooperation

Use black / blue ball pens only. Right

Wrong $\ominus \varnothing \otimes$

Survey Tag
\begin{tabular}{|l|l|l|}
\hline & & \\
\hline (0) & (0) & (0) \\
(1) & (1) & (1) \\
(2) & (2) & $(2)$ \\
(3) & (3) & $(3$ \\
(4) & (4) & $(4)$ \\
(5) & (5) & (5) \\
(6) & (6) & $(6$ \\
(7) & (7) & $(7$ \\
(8) & (8) & (8) \\
(9) & (9) & (9)
\end{tabular}

\begin{tabular}{|c|c|c|c|c|c|c|}
\hline \multicolumn{2}{|c|}{$\begin{array}{l}\text { Strongly } \\
\text { Disagree } \\
\text { 非常不同意 }\end{array}$} & \multicolumn{4}{|c|}{$\begin{array}{r}\text { Strongly } \\
\text { Agree } \\
\text { 非常同意 }\end{array}$} & \multirow{2}{*}{$\begin{array}{r}\text { N/A } \\
\text { 不道用 } \\
\text { N/A }\end{array}$} \\
\hline 1 & 2 & 3 & 4 & 5 & 6 & \\
\hline 1. $\bigcirc$ & 0 & 0 & 0 & 0 & 0 & 0 \\
\hline 2. 0 & 0 & 0 & 0 & 0 & 0 & 0 \\
\hline 3. $\bigcirc$ & 0 & 0 & 0 & 0 & 0 & 0 \\
\hline 4. $\bigcirc$ & 0 & 0 & 0 & 0 & 0 & 0 \\
\hline 5. $\bigcirc$ & 0 & 0 & 0 & 0 & 0 & 0 \\
\hline 6. 0 & 0 & 0 & 0 & 0 & 0 & 0 \\
\hline 7. $\bigcirc$ & 0 & 0 & 0 & 0 & 0 & 0 \\
\hline 8. $\bigcirc$ & 0 & 0 & 0 & 0 & 0 & 0 \\
\hline $9 . \bigcirc$ & 0 & 0 & 0 & 0 & 0 & 0 \\
\hline 10.0 & 0 & 0 & 0 & 0 & 0 & 0 \\
\hline 11.0 & 0 & 0 & 0 & 0 & 0 & 0 \\
\hline 12.0 & 0 & 0 & 0 & 0 & 0 & 0 \\
\hline
\end{tabular}

Effort spent on the course:

13. How many assigned texts (even unfinished) have you read in the whole course? 你在整個課程毫閲讀了多少指定的文本(包 括未完成的？

$\begin{array}{cccccc}0-1 & 2-3 & 4-5 & 6-7 & 8-9 & \geq 10 \\ 0 & 0 & 0 & 0 & 0 & 0\end{array}$

14. How many Chinese translations have you read in the whole course? 你在整個課程裹閱讀了多少篇文本的中譯本?

$\begin{array}{cccccc}0-1 & 2-3 & 4-5 & 6-7 & 8-9 & \geq 10 \\ 0 & 0 & 0 & 0 & 0 & 0\end{array}$

15. How much of the assigned texts have you read per week? 你每週完成了多少指定的文本?
$0 \%$
$1-20 \%$
$21-40 \%$
$41-60 \%$
$61-80 \%$
$81-100 \%$

16. How much time per week have you spent on understanding the texts? 你每週大約花多少時間理解文本?

$<1$ hour $\quad 1$ to $<2$ hours $\quad 2$ to $<3$ hours $\quad 3$ to $<4$ hours $>4$ hours

$\begin{array}{lllll}0 & 0 & 0 & 0 & 0\end{array}$

17. What percentage of the lectures have you attended? 你出席了多少課堂請課?
$0 \%$
$1-20 \%$
$21-40 \%$
$41-60 \%$
$61-80 \%$
$81-100 \%$
$\mathrm{O}$
$\mathrm{O}$
0
$\mathrm{O}$
0
$\mathrm{O}$

Please answer the questions at the back of the page. 蔳填答背面的問題 。 


\begin{tabular}{|c|c|c|c|c|c|c|c|c|c|c|c|c|c|c|c|}
\hline \multirow[t]{2}{*}{ Learning Method } & \multicolumn{5}{|c|}{$\begin{array}{l}\text { This learning method } \\
\text { facilitates my understanding } \\
\text { of the subject matter. }\end{array}$} & \multicolumn{5}{|c|}{$\begin{array}{l}\text { This learning method is } \\
\text { interesting. }\end{array}$} & \multicolumn{5}{|c|}{$\begin{array}{l}\text { Is the time spent on this } \\
\text { learning method adequate? }\end{array}$} \\
\hline & \multicolumn{10}{|c|}{ ( $1=$ strongly disagree; $5=$ strongly agree) } & \multicolumn{5}{|c|}{ Too little---Appropriate----Too much } \\
\hline \multicolumn{16}{|l|}{ Lecture } \\
\hline Listening to background information & (1) & & (3) & & (5) & (1) & (2) & (3) & (4) & (5) & (1) & (2) & (3) & (4) & (5) \\
\hline Listening to textual explanation & (1) & (2) & (3) & (4) & (5) & (1) & (2) & (3) & (4) & (5) & (1) & (2) & (3) & (4) & (5) \\
\hline Listening to the extended implications & (1) & (2) & (3) & (4) & (5) & (1) & (2) & (3) & (4) & (5) & (1) & (2) & (3) & (4) & (5) \\
\hline \multicolumn{16}{|l|}{ Tutorial } \\
\hline Listening to teacher's explanation & (1) & (2) & (3) & (4) & (5) & (1) & (2) & (3) & (4) & (5) & (1) & (2) & (3) & (4) & (5) \\
\hline Participating in in-class activity & (1) & (2) & (3) & (4) & (5) & (1) & (2) & (3) & (4) & (5) & (1) & (2) & (3) & (4) & (5) \\
\hline Participating in small group discussion & (1) & (2) & (3) & (4) & (5) & (1) & (2) & (3) & (4) & (5) & (1) & (2) & (3) & (4) & (5) \\
\hline Participating in whole class discussion & (1) & (2) & (3) & (4) & (5) & (1) & (2) & (3) & (4) & (5) & (1) & (2) & (3) & (4) & (5) \\
\hline Watching video & (1) & (2) & (3) & (4) & (5) & (1) & (2) & (3) & (4) & (5) & (1) & (2) & (3) & (4) & (5) \\
\hline Attending quiz & (1) & (2) & (3) & (4) & (5) & (1) & (2) & (3) & (4) & (5) & (1) & (2) & (3) & (4) & (5) \\
\hline \multicolumn{16}{|l|}{ Outside class } \\
\hline Reading assigned/related texts & (1) & (2) & (3) & & (5) & (1) & (2) & (3) & & (5) & & & & & \\
\hline Writing reflections & (1) & (2) & (3) & (4) & (5) & (1) & (2) & (3) & (4) & (5) & & & & & \\
\hline Participating in online discussion & (1) & (2) & (3) & (4) & (5) & (1) & (2) & (3) & (4) & (5) & & & & & \\
\hline Discussing with peers/ teacher outside class & (1) & (2) & (3) & (4) & (5) & (1) & (2) & (3) & (4) & (5) & & & & & \\
\hline
\end{tabular}

